\title{
Different roles for ipsilateral positive feedback and commissural inhibitory networks in oculomotor velocity to position neural integration
}

\author{
Keiichiro Inagaki ${ }^{*}$ Yutaka Hirata* \\ From 24th Annual Computational Neuroscience Meeting: CNS*2015 \\ Prague, Czech Republic. 18-23 July 2015
}

Saccadic eye movements are made about twice a second to shift our gaze either consciously or unconsciously. Brainstem burst neurons trigger each saccade with a bursting activity closely related to saccadic velocity that must be transformed into persistent firing activity to maintain post-saccadic eye position. A conceptual neural mechanism achieving this velocity to position integration is the oculomotor neural integrator (NI). Neurons in the nucleus of prepositus hypoglossi (NPH) in mammals and equivalently Area I (AI) in goldfish have been demonstrated to exhibit persistent activity relating to eye position. Ipsilateral positive feedback found in NPH and AI [1], and commissural inhibition between these bilateral areas [2] are proposed to be the two candidate neuronal networks for the integration. However, how these networks contribute to generate persistent firing is still unknown. Recent behavioral and optogenetic experiments demonstrated that eye position holding properties are individually modifiable for nasal and temporal hemi-fields of the eye, thereby suggesting existence of at least two NIs in each nucleus [3,4]. In the present study, we constructed a NI neuronal network model closely following anatomical and physiological evidence to better understand the roles of the two NI networks.

The model consists of an excitatory burst neuron (EBN), an inhibitory burst neuron (IBN), a tonic neuron (TN), and a bilateral NI network in which 15 integrator neurons (INs) are included unilaterally. Each IN receives input from TN, EBN, and IBN, and also has positive recurrent feedback connections from all ipsilateral INs including commissural inhibitory connections from all contralateral INs. The output of EBN, IBN, and each NI

\footnotetext{
* Correspondence: Inagakikay@isc.chubu.ac.jp; yutaka@isc.chubu.ac.jp Department Robotic Science and Technology, Chubu University, Kasugai,
} Aichi, 487-8501, Japan are weighted-summed at a motor neuron whose output is sent to an eye plant model to simulate eye movements. These neuron models are described as conductancebased spiking neurons. Synaptic weights in the model were carefully tuned to reproduce saccades and post-saccadic stable eye positions. Following individual modification of either the synaptic weights of ipsilateral feedback connection or those of commissural inhibition we measured post-saccadic eye position drift.

Simulation results showed that persistent firing activity of INs is maintained principally by the ipsilateral positive feedback. By contrast, commissural inhibition contributed mainly to null eye position which is the asymptote from which the NI becomes leaky. These findings are the first demonstration by a NI neuronal network model assigning specific and different roles to the ipsilateral positive feedback and the commissural inhibition. In future work, we will use this model to evaluate the elective eye holding properties within the two hemi-field NIs.

\section{Acknowledgement}

We thank Prof. Robert Baker for his valuable comments on this research. This work was supported by JSPS KAKENHI Grant Number 24300115 (to Y. Hirata).

Published: 18 December 2015

\section{References}

1. Seung HS, Lee DD, Reis BY, Tank DW: Stability of the memory of eye position in a recurrent network of conductance-based model neurons. Neuron 2000, 26(1):259-271.

2. Aksay E, Olasagasti I, Mensh BD, Baker R, Goldman MS, Tank DW: Functional dissection of circuitry in a neural integrator. Nature Neuroscience 2007, 10(4):494-504.

3. Okamura N, Baker R, Hirata Y: Monocular eye position specificity in the oculomotor neural integrator. BMC Neuroscience 2011, 12(Suppl 1):151. 
4. Goncalves PJ, Arrenberg AB, Hablitel B, Bair H, Machens CK: Optogenetic perturbations reveal the dynamics of an oculomotor integrator. Frontiers in Neural Circuits 2014, 8(10):1-21.

doi:10.1186/1471-2202-16-S1-P100

Cite this article as: Inagaki and Hirata: Different roles for ipsilateral positive feedback and commissural inhibitory networks in oculomotor velocity to position neural integration. BMC Neuroscience 2015 16(Suppl 1): P100.

Submit your next manuscript to BioMed Central and take full advantage of:

- Convenient online submission

- Thorough peer review

- No space constraints or color figure charges

- Immediate publication on acceptance

- Inclusion in PubMed, CAS, Scopus and Google Scholar

- Research which is freely available for redistribution

Submit your manuscript at www.biomedcentral.com/submit
Ciomed Central 